Психология. Журнал Высшей школы экономики,

2021. T. 18. № 3. C. 431-450. DOI: 10.17323/1813-8918-2021-3-431-450

\title{
СОЦИАЛЬНО-КОГНИТИВНАЯ КОНЦЕПЦИЯ ЦИФРОВОЙ СОЦИАЛИЗАЦИИ: НОВАЯ ЭКОСИСТЕМА И СОЦИАЛЬНАЯ ЭВОЛЮЦИЯ ПСИХИКИ
}

\author{
Г.У. СОЛДАТОВА ${ }^{\mathrm{a}, \mathrm{b}}$, А.Е. ВОЙСКУНСКИЙ \\ ${ }^{a}$ Московский государственный университет имени М.В. Ломоносова, 119991, Россия, Москва, \\ Ленинские горы, 1 \\ ${ }^{b}$ Российская академия народного хозяйства и государственной службы при Президенте Россий- \\ ской Федеращии, 119571, Россия, Москва, просп. Вернадского, д. 84
}

\section{Резюме}

В рамках трансдисциплинарного подхода и с опорой на многолетние эмпирические исследования разработана социально-когнитивная концепция цифровой социализации, отражающая процесс адаптации изменяющегося человека к возможностям и рискам динамичной социотехнологической среды. Ключевой элемент концепции цифровой социализации - гиперподключенная, технологически достроенная цифровая личность как часть личности реальной; она отражает современный этап социальной и когнитивной эволюции человеческой психики, когда развивающееся сознание фактически сращивается с внешними орудиями (гаджетами) и знаковой реальностью (Интернетом). Цифровые технологии интегрируются в нашу когнитивную и социальную систему, определяя цифровое расширение (достройку) человека. Ключевые измерения цифровой социализации - гиперподключенность к Интернету, смешанная реальность, расширенная личность и цифровая социальность. Существование в смешанной реальности и гиперподключенность к Интернету - не только базовые и определяющие характеристики цифровой социализации и взрослого, и ребенка, но и главная основа изменений, которые происходят сегодня с человеком. Расширенное Я - постоянно развивающееся и совершенствующееся культурное орудие - формируется в своем социотехнологическом воплощении и меняет экосистему человека. Формирующаяся и трансформирующаяся личность расширяется и вбирает в себя в качестве значимого звена техносистему, способствующую реализации психологических механизмов экстериоризации и включающую цифровые устройства и компьютерные программы вместе со способами их применения. Новый антропологический тип цифрового человека - «человек подключенный и достроенный» - обитает во многих реальностях и взаимодействует уже и с неживыми системами (чат-ботами, бытовыми роботами и др.): требуется смена парадигм, обновление теоретико-методологических моделей. Это определяет кумулятивность теоретико-методологического подхода, главной опорой которого выступает разработанная Л.С. Выготским и его последователями культурно-историческая теория развития психики, впитавшая в себя классические и современные гуманитарные и естественно-научные концепции. Данный подход - перспективный базис для исследования особенностей цифровой реальности, способный выдержать вызовы «новой нормальности».

Ключевые слова: социализация, цифровая социализация, трансдисциплинарность, культурноисторическая психология, экстернализация, техносистема, гиперподключенность, расширение личности, достроенное Я, смешанная реальность, новая нормальность, цифровая социальность.

Исследование выполнено при поддержке РНФ, проект № 18-18-00365 «Цифровая социализация в культурно-исторической перспективе: внутрипоколенческий и межпоколенческий анализ». 


\section{Введение}

Для истории человечества развитие постиндустриальной цивилизации сначала как информационной (Тоффлер, 2002), а в настоящее время как сетевой и переходящей в цифровую эру (Кастельс, 2016), подобно смене геологических эпох в истории Земли. Кардинальные изменения образа жизни человека произошли и продолжают происходить в контексте последствий третьей индустриальной революции, начавшейся в 1960-е гг. (Шваб, 2016). На глазах ныне живущих представителей старших поколений произошел впечатляющий технологический переход от аналогового мира к цифровому; молодежь, подростки и дети, а также родители современных детей - активные участники изменения образа жизни под влиянием цифровых трансформаций.

Их результатом стало не только появление новых устройств и технологических возможностей, но и бурное развитие различных цифровых пространств, определяющих новые формы социального взаимодействия между их участниками. Постоянные спутники современного человека - смартфон и компьютер - на первый взгляд кажутся лишь частью обычной жизни. Но уникальность цифровой эпохи в том, что у различных поколений традиционные формы социализации не только соседствуют, но все чаще дополняются, конкурируют и частично замещаются новыми формами обретения жизненного опыта - цифровой социализацией. Особенно активно это взаимодействие происходит у современных детей и подростков - передового отряда человечества по освоению цифровых технологий (Солдатова и др., 2017).

Термин «цифровая социализация» недавно введен в научный дискурс и рассматривается как опосредованный инфокоммуникационными технологиями процесс овладения и присвоения индивидом социального опыта и социальных связей, которые он приобретает в онлайн-контекстах, воспроизводство этого опыта и социальных отношений в множественной реальности окружающего мира (Солдатова, 2018). В контексте изучения подрастающего поколения этот термин все чаще употребляется наряду с «информационной социализацией» (Е.П. Белинская, Т.Д. Марцинковская, С. Ливингстон, Ш. Тёркл и др.).

Для понимания психологических особенностей взаимодействия человека с цифровыми технологиями и векторов его социального развития в современном обществе необходимо формирование рабочей концепции цифровой социализации, обеспечивающей теоретико-методологическую основу исследования динамичного процесса адаптации меняющегося человека к непрерывно меняющейся повседневности. Такая задача требует перехода из контекста моно- и междисциплинарных исследований в контекст трансдисциплинарности, что открывает возможности взаимодействия разных дисциплин при изучении сложных проблем развития человека, технологий и общества и построения концепции цифровой социализации.

Термин «трансдисциплинарность» как следующий вслед за междисциплинарным подходом этап научных исследований был представлен Жаном Пиаже еще в 1970 г. как подход, определяющий отношения внутри глобальной 
системы научных знаний без строгих границ между дисциплинами. Современные исследователи отмечают, что трансдисциплинарность как «конструкт, несущий пафос подвижности, полноты и целостности знания» означает «движение сквозь дисциплины», их «созидательный полилог» предполагает прежде всего «установку на открытость», «демократичность знания и его полифонию» и в связи с этим - изменение стиля научного мышления в цифровую эпоху (Бажанов, 2015; Гусельцева, 2015; Клочко, 2012).

В XXI в. трансдисциплинарность обладает потенциалом определять облик науки в недалеком будущем и предлагать обоснованные способы решения ключевых комплексных проблем природы и общества путем взаимодействия различных научных дисциплин. В трансдисциплинарном контексте уже развиваются проекты, связанные с проблематикой генома, нейроинтерфейсом, искусственным интеллектом, проблемой сознания. Трансдисциплинарный подход позволяет подойти к анализу сложной проблемы социализации в условиях множественной реальности в разных средах (реальностях) - в физическом мире и в символьном пространстве Интернета, одновременно на когнитивном и социальном уровнях, а также в контексте эволюции общества в целом.

В данной статье с опорой на психологию и на основе трансдисциплинарного подхода представлены итоги усилий в области разработки теоретической концепции цифровой социализации по влиянию цифровых трансформаций на человека и его поведение. Такая концепция необходима для понимания проблемного феноменологического поля, определяемого включенностью представителей разных поколений в процессы цифровых трансформаций; концепция позволяет соотносить «старые» (относящиеся к традиционной социализации) и новые «цифровые» понятия, феномены и смыслы. Такое соотнесение, выполненное в контексте полученных в последние годы эмпирических фактов,- это перспектива генерировать гипотезы для новых исследований в условиях роста сложности, неопределенности, непредсказуемости и стремительных изменений не только окружающего мира, но и самого человека (Асмолов, 2018; Асмолов, Асмолов, 2019).

Разработка концепции предполагает поиск ответов на следующие вопросы. Какова теоретико-методологическая основа, позволяющая в трансдисциплинарном ключе исследовать проблему взаимодействия человека с цифровыми технологиями и вопросы социальной эволюции психики в постоянно изменяющемся мире? Можно ли говорить о новой экологической системе существования человека в условиях стремительных цифровых трансформаций и роста «гиперподключенности» к Интернету? Каковы основные измерения цифровой социализации, определяющие особенности и векторы ее формирования и характеризующие человека как субъекта социализации в цифровой среде?

\section{Цифровая социализация: методологические подходы}

Понимание технологий как культурных орудий и первые заметные изменения привычных форм социального взаимодействия под влиянием цифровых 
трансформаций побудили исследователей обратиться к идеям Л.С. Выготского (Войскунский, 2010; Коул, 1997; Griffin et al., 1992). Авторы данной статьи, занимаясь киберпсихологией, с годами укрепились во мнении, что методологической базой изучения социализации в цифровом мире должна оставаться культурно-историческая психология Л.С. Выготского, заложившая основу анализа познавательной деятельности человека как результата взаимодействия с объектами окружающего мира и как продукта исторического социального развития людей (Выготский, 1982). Усиливает эту методологию историко-эволюционный подход А.Г. Асмолова, позволяющий рассматривать механизмы развития психики и личности в контексте эволюции общества в эпоху роста неопределенности, волатильности и сложности трансформирующихся структур, ориентированных на непредсказуемое будущее (Асмолов, 2018; Асмолов, Асмолов, 2019).

Лучше понять процессы социализации в современном мире позволяет оптика гипотезы «новой нормальности», предложенная в период экономического кризиса 2008 г. для объяснения явлений в период перемен и трансформаций общества и связанная с разрушением старых стандартов и норм (Buheji, Sisk, 2020). В период пандемии эта гипотеза вновь вышла на первый план. Под «новой нормальностью» сегодня понимают не только экономические, но и социальные и психологические изменения в разных сферах жизни. Оптика «новой нормальности» требует смены привычного взгляда на окружающий мир, нового набора правил и идей. Дискурс «новой нормальности» направлен на переосмысление прошлого и утверждение в качестве стандарта настоящего. В этом контексте исчезает понимание «нормальности» в прежнем смысле. Важнейший тренд «новой нормальности» в VUCA-мире - это цифровые трансформации, определяющие перестройку нашей повседневности и меняющие картину мира. Применительно к процессу социализации новая нормальность означает, что ранее принятые образцы и законы успешной социализации, а также нормы психологии и педагогики развития, задававшие рамки формирования личности от рождения до смерти, перестают соответствовать духу времени (Солдатова, 2018).

Вышесказанное добавляет остроты вопросу о применении норм доцифрового детства к современному ребенку. В «новой нормальности» норма динамична и не константна. Действительно, изменившаяся социальная ситуация развития человека требует пересмотреть взгляды на процессы социализации, способствующие адаптации в технологически насыщенном, стремительно трансформирующемся обществе. Последователи У. Бронфенбреннера, автора теории экологических систем, который развивал концепцию социальной ситуации развития Л.С. Выготского (Bronfenbrenner, 1979, 2004), между развивающейся личностью и четырьмя известными системами (микро-, мезо-, экзо- и макросистемами) поставили еще одну - техносистему, состоящую из многочисленных цифровых устройств, различного рода программ, цифровых платформ и сред: она рассматривается как результат изменения экосистемы человечества в условиях цифровых трансформаций (Johnson, Puplampu, 2008). Результаты наших исследований подтверждают, что техносистема ста- 
новится важнейшей частью современной культуры, главным опосредующим звеном в сложном хронотопе существования личности в современном мире и значимой частью экосистемы формирующейся личности (Солдатова и др., 2017). В частности, исследования свидетельствуют, что техносистема, опосредуя взаимодействие ребенка с окружающим миром, снижает возможности конструирования значимыми взрослыми цифрового детства в целом и в частности зоны ближайшего развития ребенка - все эти процессы происходят сегодня по иным законам, нежели у представителей предыдущих поколений (Там же).

Рассмотрение техносферы как важной части новой системы экологии человека продолжают работы в такой быстро развивающейся области трансдисциплинарных исследований, как медиаэкология, или экология средств коммуникации (Маклюэн, 2005; Кастельс, 2016). М. Маклюэн подчеркивал, что средство передачи сообщения (артефакт) не менее существенно, чем содержательная сторона передаваемого сообщения (контент) (Маклюэн, 2007). Признавая составным элементом коммуникативной культуры всякий артефакт, посредничающий в акте передачи контента, медиаэкологи значительно развили проблематику коммуникативного опосредования, обозначив в качестве «внешних расширений» (М. Маклюэн) человека такие технологии, как письменность, книгопечатание или телевидение; в настоящее время это в первую очередь интернет-технологии. Оформляющаяся ныне «экология артефактов» вносит заметный вклад в прогресс нейрокогнитивных наук, в том числе в понимание особенностей цифровой социализации (А.Г. Асмолов, М. Коул, Л. Малафурис, М.В. Фаликман и др.).

На сегодняшний день наполнение техносистемы - это не только компьютеры и смартфоны, социальные сети, мессенджеры, облачные хранилища, электронные книги, видеоигры, электронные игрушки, программы искусственного интеллекта и др., но и способы работы с ними. При этом техносистема как совокупность технологий - это установление активного интерфейса (набора средств) индивида, подключенного или гиперподключенного к Интернету как сложному и многофункциональному инструменту, с окружающим миром; это также тот мост, который определяет конвергенцию двух главных существующих сегодня реальностей - онлайн и офлайн - и служит основой формирования смешанной, или совмещенной, реальности.

Согласно одному из ключевых положений культурно-исторической психологии, деятельность опосредствована внутренними и внешними «искусственными приспособлениями», которые «по аналогии с техникой могут быть по справедливости условно названы психологическими орудиями или инструментами» (Выготский, 1982, с. 103). В соответствии с культурно-историческим подходом эти орудия, социальные по своей сути, возникают и осваиваются в процессе социализации, помогая индивиду овладевать собственными психическими процессами и преобразовывать их. Цифровые устройства и цифровые платформы как культурные средства (орудия) «подключенного» индивида опосредуют психические функции, новые виды деятельности и социального взаимодействия, новые культурные практики (А.Г. Асмолов, А.Е. Войскунский, 
В.П. Зинченко, М. Коул, Дж. Макгонигал, О.В. Рубцова, Г.У. Солдатова, О.К. Тихомиров, М.В. Фаликман, Ю. Энгестрём, С. Ливингстон, Ш. Тёркл и др.).

Важнейшая составляющая техносистемы - знаковая реальность пространства Интернета, представленная в многочисленных онлайн-средах. Л.С. Выготский отводил наиболее значимое место семиотическим орудиям - знакам и знаковым системам. В связи с этим следует говорить не просто о техносистеме, а об Интернете, понимаемом как социотехническая система взаимосвязанных элементов цифровых технологий, опирающаяся на знаковые системы. В соответствии с мемом «The medium is the message», или «средство передачи сообщения есть сообщение» (М. Маклюэн), цифровые устройства сочетают в себе орудийные и знаковые компоненты (Рубцова, 2019). Усложняющиеся семиотические системы - важнейший фактор, способствующий развитию и трансформации высших психических функций. Тем самым с психологической точки зрения применение Интернета - современный этап знакового опосредствования деятельности.

Л.С. Выготский, говоря о психологических орудиях, проводит аналогию с техникой: «Будучи включено в процесс поведения, психологическое орудие так же видоизменяет все протекание и всю структуру психических функций... как техническое орудие видоизменяет процесс естественного приспособления, определяя форму трудовых операций» (Выготский, 1982, с. 103). Психолого-генетический (в понимании Л.С. Выготского) анализ показывает, каким образом предназначенные для подчинения внешней среды орудия способствуют развитию психических аналогов и внутренних (психологических) орудий, опираясь на которые человек занимается переструктурированием техносистемы и тем самым преобразует собственную психику.

Цифровые орудия отличны от традиционных: они многофункциональны, совмещают сигнальные и контрольные функции, обладают элементами искусственного интеллекта, персонализированы, мобильны, могут быть использованы в режиме обучения и при принятии решений; будучи орудийными помощниками, они являются знаковыми инструментами.

Так, в процессе «традиционной» социализации интернализированные психологические орудия (собственно язык и правила общения, цифры для счета, схемы, диаграммы, письмо, мнемотехнические приемы и др.), формирующиеся в результате трансформации внешних социальных форм во внутренние, в итоге становятся индивидуальным свойством и способностью к новым для индивида когнитивным и социальным действиям вовне. Таким образом, сознание индивида экстернализуется - «размыкается» во внешний мир.

Экстерналистская философско-методологическая позиция привлекает внимание исследователей в связи с дискутируемым представлением о расширенном сознании, согласно которому в формировании высших психических функций и психических состояний принимает участие не только мозг человека, не только его тело, но и объекты окружающей среды (например, письменные источники или электронные гаджеты), в том числе разнообразные технологические артефакты, взаимодействие с которыми расширяет сознание за 
пределы организма. Организм и объект создают спаренную систему, которая может рассматриваться как общая когнитивная система (Clark, Chalmers, 1998). Подобная позиция, однако, представляется однобокой (Иванов, 2019; Файола и др., 2016). Предложенный Л.С. Выготским культурно-исторический подход на самом деле удовлетворяет основным критериям обоснования теории расширенного сознания и представляет, по мнению Д.В. Иванова, активный социальный экстернализм. Это выгодно отличает данный подход как от концепции экстернализма, разработанной Э. Кларком и Д. Чалмерсом, в которой не уделяется должного внимания социальным формам развития психики, равно как и от заявленных в философской литературе вариантов социального экстернализма, поскольку они исходят при этом не более чем из пассивной роли социума в формировании когнитивных процессов (Иванов, 2019).

Культурно-историческая психология обращена к активным социальным формам развития психики. Это существенно для построения концепции цифровой социализации: с одной стороны, рассматривается активность личности как социального субъекта, с другой - онлайн-пространство выступает активной, убеждающей и влиятельной социально-технологической средой, направленной на «улучшение» («enhancement») человека, в определенном смысле на развитие «постчеловека» и «постчеловечества» (Файола и др., 2016). Такой взгляд позволяет говорить о соединении когнитивного и социального, основой которого становится цифровое расширение личности современного челове$\kappa a$, в значительной степени определяющее новые правила восприятия своего социального Я и особенности социального взаимодействия - т.е. построения новой социальности - цифровой. Доказательства этого мы видим в уже зафиксированных эффектах или феноменах. Например, в «эффекте Юлия Цезаря», когда технологический рост, насыщенная информационная среда, множественная и смешанная реальности, требования нового образа жизни заставляют и взрослых, и детей все чаще действовать в формате многозадачности вне зависимости от их способностей к такому формату (Солдатова и др., 2020). Или в «Гугл-эффектах», когда содержание нашей памяти ассоциируется с содержанием поисковых систем и рассматривается как достояние человека, а способность к эффективному поиску повышает самооценку: люди начинают оценивать себя выше в сравнении с теми, кто выполняет задание, не прибегая к поиску в файлах или на сайтах (Sparrow et al., 2011). Или «эффект iPhone»: при короткой беседе незнакомых ранее людей степень их взаимопонимания и доверия друг другу снижается, когда в поле их зрения демонстративно размещают смартфон (Przybylski, Weinstein, 2013).

Такого рода трансформации высших психических функций, а также цифровую сощиальность как продукт цифровой социализации следует рассматривать как часть глобального эволюционного процесса - результата социокультурной эволюции психики, происходящей в процессе адаптации человека к многоаспектной и насыщенной цифровой среде посредством поиска новых способов управления памятью, вниманием, мышлением и социальным познанием. Это психологическая основа новой экологической среды современного человека. 
Все эти процессы отчетливо видны при исследовании цифрового детства. В контексте взаимодействия традиционной и цифровой социализации ребенок одновременно, во-первых, овладевает собственными когнитивными процессами с помощью психологических орудий, которые он осваивает с помощью взрослых в процессе взаимодействия, а во-вторых, создает новые способы управления своими когнитивными процессами посредством цифровых инструментов как культурных орудий, которые он нередко осваивает самостоятельно или при недостаточном посредничестве со стороны значимых взрослых (Солдатова и др., 2017).

Таким образом, рассматривая цифровую социализацию в целом как процесс адаптации изменяющегося человека к возможностям и рискам динамичной социотехнологической среды, среди основных характеристик современного человека как субъекта цифровой социализации и ее главных измерений мы выделяем гиперподключенность к Интернету как к многофункциональному орудию, активность человека как субъекта деятельности в смешанной/ совмещенной реальности, социотехнологическую достройку, или расширение личности, и цифровую социальность. На их анализе мы подробнее остановимся ниже.

\section{Цифровая социализация в условиях гиперподключенности и конвергенции онлайн- и офлайн-миров}

Одна из важных особенностей современных поколений - высокая оснащенность цифровыми устройствами, подключенными к Интернету. Таким образом, главный актор современного мира - человек «подключенный», который «всегда на связи». Все чаще говорится о «гиперподключенности» (Brubaker, 2020; Otrel-Cass, 2019), которая соответствует высокому уровню пользовательской активности и максимальным показателям «экранного времени», проведенного перед экранами смартфона, компьютера или планшета (Brubaker, 2020; Otrel-Cass, 2019; Floridi, 2015). По нашим данным, показатель гиперподключенности в 2019 г. у российских подростков и взрослых достигал 8-10 часов в сутки, что соответствует половине времени бодрствования человека. Наблюдая за этим показателем с 2009 г., мы зафиксировали отчетливую тенденцию его роста (Солдатова и др., 2017). Например, за 6 лет (2013-2019) уровень гиперподключенности у подростков и их родителей вырос более чем в два раза. В 2019 г. гиперподключенным был каждый четвертый подросток 14-17 лет (Солдатова, Рассказова, 2020). Во время пандемии в 2020 г. уровень цифровой «подключенности» вырос и стал одним из важнейших факторов, определяющих образ жизни современного человека.

Достичь уровня гиперподключенности - это как «перейти Рубикон», пройти точку невозврата: человек начинает проводить в цифровом мире не просто часть своей жизни, а время, сопоставимое с его активностью в реальном мире. Возникает закономерный вопрос: сказывается ли подобный стиль жизни на формировании мозговых механизмов? Исследования в этой области ведутся. Так, опубликованы данные, согласно которым количество экранного 
времени (просмотр телевизора и видео, участие в компьютерных играх, набор текстов, участие в видеочатах и в социальных сетях) - достаточно значимый фактор, возможно, определяющий анатомическое развитие головного мозга подростка (Paulus et al., 2019).

Посредством подключенности к Интернету мир превращается в совмещенную или смешанную реальность (Войскунский, 2010; Floridi, 2015; Skarbez et al., 2021). До сих пор эта тема была значима в основном в технологической плоскости, но сегодня все отчетливее осознается, что представления о реальности постоянно изменяются, а границы между реальностями онлайн и офлайн все больше размываются. Действительно, можно совместить прогулку со стримом о прогулке, во время ланча смотреть спортивное соревнование и обмениваться комментариями с другими зрителями, на школьном уроке играть в компьютерную игру. В 2019 г. каждый второй российский ребенок и каждый пятый взрослый осознавали, что живут в смешанной онлайн/офлайнреальности (Солдатова, Рассказова, 2020). Еще недавно не выглядели нелепыми споры о том, сколько часов в день допустимо проводить онлайн, а детей наказывали лишением «компьютерного» времени. Теперь же многие владельцы смартфонов фактически круглосуточно «на связи» (онлайн), не переставая при этом заниматься бытовыми делами (офлайн).

Не случайно Л. Флориди вводит термин «onlife» (Floridi, 2014, p. 43), обозначающий смешение реальностей. Перспектива onlife обещает изменить массовые представления о материальной и нематериальной стороне жизнедеятельности и в целом о разных и пересекающихся реальностях (Otrel-Cass, 2019; Floridi, 2015). В смешанной реальности объединены и привычная, и виртуальная (частично или полностью формируемая компьютером), и дополненная (augmented) реальности, последняя включает виртуальный контент, наложенный на реальную среду. В промежутке между «реальной виртуальностью» и «виртуальной реальностью» формируются индивидуальное ощущение «присутствия» (presence) в смешанной среде и способность к иммерсии (погружению) в нее (Войскунский, 2010).

Смешанная реальность как социальное и психологическое пространство жизнедеятельности человека - перспективная область научного поиска. Одной из важных попыток осмысления данного феномена является исследование возможности переноса психологических феноменов и конкретных навыков и умений из онлайн в офлайн, и наоборот. Данной задаче посвящены работы Н.В. Авербух, Б.Б. Величковского, Дж. Ланье, Дж. Макгонигал, Г.Я. Меньшиковой, М. Алканиса, С. Бушара, Х. Эршона, Дж. Ривы, М. Слэйтера и др. Так, удалось доказать воздействие на параметры самооценки испытуемых в онлайн-среде и сохранить в физической реальности зафиксированный онлайн-эффект снижения либо повышения самооценки; данный результат получил название «эффект Протея» - древнегреческого бога, способного являться в разных обличиях (Yeе, 2014).

Среда onlife обитания взрослых и детей, источник их развития и важнейший фактор социализации, соединяет традиционную социализацию с цифровой. Только посредством соединения этих аспектов социализации возможна 
адаптация к смешанной реальности современного мира. Смешанная реальность - особенно в условиях пандемии - становится типичной средой обитания взрослых и детей, пространством их социализации, объединяющим «традиционные» и цифровые аспекты. Вопреки нередко звучащему мнению, согласно которому это единое информационное пространство, заметим, что смешанная реальность не ограничивается поиском и предоставлением информации, это реальность одновременно интеллектуальной и эмоциональной активности, социальных контактов, учебы, личностного роста, формирования чувства уверенности в себе и компетентности, а также условного присутствия реально отсутствующих значимых людей.

Пытаясь исследовать специфику смешанной реальности, мы выявили, что рост «подключенности» позволяет говорить не просто о количественном накоплении экранного времени, а о трансформации пользовательской активности как отдельной от офлайн-деятельности в новые формы деятельности в смешанной реальности. На объективном уровне это проявляется в дополнении различной онлайн-активностью многих видов привычных повседневных активностей в физическом мире, не требующих высокой концентрации внимания (например, прием пищи, переезды в транспорте и др.). А на субъективном уровне - в переживании подростками реальности как смешанной, а не разделенной на онлайн и офлайн (Солдатова, Рассказова, 2020).

Н.Н. Вересов, анализируя категорию «переживание» в культурно-исторической психологии, отмечает, что Выготский определяет переживание как своеобразную преломляющую призму, благодаря которой те или иные компоненты социальной среды приобретают направляющее значение в ходе развития (Вересов, 2016, с. 141). Именно переживание как эмоциональное и когнитивное отношение субъекта к среде и деятельности в ней (Василюк, 1984), как важный механизм социализации, особенно для детей и молодежи (Марцинковская, 2009), может рассматриваться в качестве психологической единицы анализа субъективного восприятия смешанной реальности, а также не только офлайн-, но и онлайн-сред.

Гиперподключенность к Интернету и пространство смешанной реальности - фундаментальные характеристики «новой нормальности». Именно на них опираются основные новации цифровой эры, которые сказываются порой неожиданным образом - на психологических состояниях современного человека.

\section{Технологическое и психологическое расширение человека: достроенное Я}

Новая экология артефактов способствует преобразованию не только когнитивных, но и личностных характеристик. Ключевым результатом цифровой социализации является цифровая личность. Феномен личности как одно из центральных и интегративных понятий в психологии становится еще более сложным, чем он был до цифровой эпохи. Несмотря на то что цифровая личность - это важнейшая составляющая «новой нормальности», изучение ее 
как целостного интегративного образования только начинается. Важнейшим ракурсом такого подхода должно стать исследование цифровой личности как важнейшего дополнения реальной личности современного человека.

Обобщая исследования киберличностей, «цифровых двойников», «цифровых близнецов», «виртуальных личностей», «сетевых самостей» и других обозначений цифровой личности, ее можно рассмотреть, во-первых, как процесс и результат постоянной оцифровки практически всех сторон нашей жизни, во-вторых, как цифровую идентификацию личности (все учетные записи, блоги, реквизиты и др.), в-третьих, как сложный результат воздействия на человека киберпространства (в том числе «новых медиа» - социальных сетей, блогосферы, электронных СМИ и др.). Наконец цифровая личность - это еще и принадлежащие человеку и подключенные к сети цифровые устройства. Все перечисленное в контексте нашего методологического подхода рассматривается как әкстернализация человека посредством техносистемы через его внешние расширения, продолжения и достройки (Л.С. Выготский, М. Маклюэн, О.К. Тихомиров, Л. Флориди и др.). Все они имеют общую основу, определяющую основные механизмы формирования и активности цифровой личности, и в то же время персонализированы в силу индивидуальных особенностей реальной личности.

Процесс расширения человека начался не сегодня. Так, неандерталец уже около 100 тысяч лет назад стал «расширяться», когда впервые использовал камень как орудие или нарисовал свой первый наскальный рисунок. В процессе социальной эволюции усложнение способов деятельности человека и достройка его посредством технологий идут параллельно. На пути к становлению творцом биосферы и ноосферы человек начал достраивать орудиями охоты и труда свою руку, различными изобретениями - сенсорные системы (пример - достройка глаза: от лупы до микроскопов и телескопов), одеждой - системы терморегуляции (Фейгенберг, 2011). Представления о расширении человека часто встречаются в сказках и мифах, а Маклюэн (2007) описывал технологические артефакты, выступающие в роли средств коммуникации как внешние продолжения человека.

В процессе своего непрерывного расширения человек сделал самый значительный шаг именно в эпоху цифровых трансформаций. Индивид в «новой нормальности» - человек, существенно расширенный за пределы своего организма, что предполагает значительное расширение его возможностей по сравнению, например, с аналоговой эпохой.

Цифровые технологии способствуют не только когнитивной, но и, например, локомоторной активности - упомянем экзоскелеты и другие бионические протезы, в том числе устройства преобразования цвета в звук для помощи страдающим цветовой слепотой: невоспринимаемый цвет переводится в звуковые волны, а человек обучается воспринимать встреченные объекты цветными или хотя бы раскрашенными (Файола и др., 2016). Имеются и более усовершенствованные протезы. Поистине, цифровые артефакты способны «расширить возможности сенсорной, нейрокогнитивной или скелетномышечной систем человеческого организма» (Там же, с. 150). 
Технологические расширения и достройки современного человека позволяют ему активно осваивать среду как онлайн, так и офлайн и чувствовать себя адекватно в смешанной реальности. В качестве эволюционного наименования активно расширяющихся посредством цифровых технологий, как бы «достраивающих» себя поколений предложено говорить о Homo sapiens perimplens - «человеке достроенном» (Фейгенберг, 2011). Таким образом, человек расширенный или достроенный - еще одно измерение цифровой социализации и значимая характеристика «новой нормальности». Такие расширения становятся частью, неотъемлемой принадлежностью человека и именно так начинают восприниматься, о чем свидетельствуют результаты исследований (Асмолов, Асмолов, 2019; Солдатова и др., 2017; Файола и др., 2016). Не только преимущества, но и необратимость этого процесса и возможную драму описал И.М. Фейгенберг: «Человек достроенный - это единый организм, а не организм, просто использующий что-то из своего окружения. Это организм, достроивший себя и уже нежизнеспособный (в своем новом качестве) без этих достроек» (Фейгенберг, 2011). Безусловно, интерес к теме социотехнологического расширения не случаен - такие процессы и их результаты, как мы отчетливо видим, существенно изменяют образ жизни человека, меняя его самого.

\section{Новая социальность как измерение цифровой социализации}

Технологическая расширенность субъекта, безусловно, ставит вопрос о том, что происходит с ним как с социальным существом. Онлайн-среда становится все более равноправным социальным и культурным пространством, влияющим и на подрастающее поколение, и на взрослых. А ее законы и правила отличаются от реального мира, порождая новую социальность. Цифровая социальность - это все то, что человек приобретает в ходе межличностного онлайн-взаимодействия и в составе различных групп в Интернете, это способы и практики самопрезентации и социальной коммуникации, новые форматы деятельности, накапливаемые социальные онлайн-контакты, освоение и реализация социальных ролей в сети, это усвоение, принятие и соблюдение норм и правил цифровой среды и выполнение на их основе различных социальных функций.

Тема цифровой социальности обширна - от проблемы самопрезентации в сети до цифрового гражданства. В рамках статьи, сужая взгляд на этот феномен, очень кратко остановимся на его рассмотрении сквозь призму метафоры человека расширенного/достроенного. Эта метафора, с одной стороны, отражает безграничные перспективы расширения его возможностей, с другой риски кардинального изменения образа жизни и его самого.

В диапазоне исследований цифровой социальности на одном из первых мест стоят вопросы возникновения новых способов отношений в условиях цифровых трансформаций. Внимание к изменению отношений возникает во всех областях жизнедеятельности современного человека. Исследователи занимаются анализом расширенного Я и новыми способами поведения чело- 
века (в целом в обществе, конкретно посредством цифровых устройств, в цифровом мире). Так, анализируется развитие личности в условиях цифрового расширения человека. Подобные процессы ведут к цифровым трансформациям личности и новым формам социальности, среди них: дематериализация (материальные артефакты превращаются в цифровые объекты - тексты, видео, фото и др.); изучение себя (путем экспериментирования со своим Я); объективация, соконструирование (новые возможности увидеть себя с точки зрения других); перевоплощение, конструирование себя (освобождение от тела, аватары и цифровые персонажи, текстовые аккаунты как развитие «бестелесности»); регуляция себя (новые способы борьбы со стрессом, тревогой, одиночеством, депрессией и др., а также с такими явлениями и феноменами, как номофобия, смартинг, инфогестия, «ожог экрана», e-mail-аллергия и др.); управление собой (ограниченный, упрощенный или регулируемый выбор); производство себя (цифровая личность производит и продает себя, приобретая влияние); количественная оценка себя (личность все чаще определяется количественными способами, селф-трекинг как часть новой социальности) (Belk, 2016; Brubaker, 2020).

Быть уверенным и адекватным в современном мире означает «быть на связи». Чем младше подростки, тем чаще они воспринимают цифровые объекты как часть своего Я: об этом свидетельствуют неразлучность с гаджетом (гиперподключенность), эмоциональная привязанность к нему и к Интернету в целом, специфические цифровые фобии - номофобия, страх остаться без доступа к социальным сетям, высокий уровень технофилии и доверия к цифровой среде, а также позитивное восприятие себя в цифровом мире по сравнению с реальным Я (Солдатова и др., 2017).

Цифровое расширение, определяющее новую социальность, происходит за счет роста онлайн-капитала. У трети российских подростков только по одной из сетей уже превышена среднестатистическая величина возможных социальных контактов в соответствии с числом Р. Данбара (Там же). Одним из доказательств интеграции техносистемы с социально-когнитивной системой человека является выявленное сближение реальной и цифровой личности (Back et al., 2010).

Риски новой социальности также связаны с процессами расширения личности, что ставит вопрос о границах и дает основания для многочисленных дискуссий, связанных с негативными явлениями, описанными рядом авторов: «цифровым слабоумием», «цифровым аутизмом», «цифровой депривацией», проблемами дереализации, цифровой деперсонализацией и другими ключевыми или частными проблемами.

В словаре В. Даля «социальность» определяется как «общественность, общежительность, гражданственность, взаимные отношения и обязанности гражданского быта, жизни» (Даль, 1980, т. 4, с. 284). Поэтому и в цифровом мире социальность в наиболее интегративном понимании - это цифровое гражданство, понимаемое как уровень готовности к ответственному, этичному, эффективному и безопасному для себя и других использованию онлайн-ресурсов (Mossberger et al., 2007). В частности, цифровое гражданство подразумевает демократический стиль сетевого поведения, т.е. горизонталь- 
ные одноуровневые связи без иерархии отношений. В рамках новой социальности осваиваются цифровые инструменты для реализации различного рода гражданских действий.

\section{Выводы}

Представленная социально-когнитивная концепция цифровой социализации, ключевым элементом которой является гиперподключенная, технологически достроенная цифровая личность как часть личности реальной, отражает современный этап социальной и когнитивной эволюции человеческой психики, когда развивающееся сознание в познавательном и коммуникативном плане фактически сращивается с внешними орудиями (гаджетами) и знаковой реальностью (Интернетом). Такой взгляд предполагает, что наряду с традиционными каналами социализации на индивида воздействуют онлайн-сервисы, причем с возрастающим ускорением; тем самым в процессы социализации вплетаются цифровые элементы. Без цифровой социализации затруднен процесс становления личности, ее интеграции в социальной системе цифрового общества; она дополняет традиционную социализацию, а развивающаяся цифровая культура дополняет офлайн-повседневность.

Конструкт «цифровая социализация» исследуется через большое количество различных феноменов, критериев и показателей на когнитивном, личностном, социально-психологическом уровнях. Все изучаемые процессы и явления - в постоянной динамике, но все же некоторые моменты сегодня просматриваются достаточно отчетливо. Выделяются ключевые для формирования личности современного человека измерения цифровой социализации: гиперподключенность к Интернету, смешанная реальность, расширенная личность и цифровая социальность. Существование в смешанной реальности и гиперподключенность к Интернету как сложному и многофункциональному инструменту - базовые и определяющие характеристики цифровой социализации. И это не только новые состояния и новые качества, присущие современному человеку - и взрослому, и ребенку, - но и главная основа тех изменений, которые происходят сегодня. Цифровые технологии встраиваются в когнитивную и социальную систему человека, интегрируются с ней, определяя цифровое расширение (достройку) человека, и видоизменяют ее.

Расширенное Я - постоянно развивающееся и совершенствующееся культурное орудие, которое, возникнув в процессе социальной эволюции человека, сегодня формируется в своем социотехнологическом воплощении и меняет экосистему человека. Явление нового антропологического типа цифрового человека - «человека подключенного и достроенного», обитающего во многих реальностях и начинающего активно взаимодействовать, в частности, с неживыми системами (чат-ботами, электронными помощниками, бытовыми роботами и др.), - потребует смены парадигм, обновления теоретических и методологических исследовательских моделей.

Рассмотрение формирования современного человека через призму гиперподключенности, не изученного ранее пространства смешанной реальности и 
беспрецедентного технологического расширения личности, которые определяют ее новую социальность, во-первых, предполагает необходимость иного взгляда на нормы когнитивного и личностного развития, во-вторых, подтверждает значимость орудийного опосредствования деятельности как одного из существенных условий не только развития психики, но и механизмов переопосредствования - включения уже опосредствованных форм деятельности в новые системы опосредствования. Поэтому закономерно намечающееся в исследованиях смещение фокуса с изучения процессов главным образом интериоризации на психологический анализ процессов экстериоризации, в частности на вопросы эффективного овладения цифровыми устройствами и техносистемой в целом.

В рамках наших исследований концепция продолжает апробироваться и корректироваться на основе получаемых эмпирических данных и экспериментальных исследований. Требует уточнения и, возможно, переосмысления целый ряд конструктов, с которыми работают исследователи, изучая личностные и когнитивные изменения у представителей разных поколений, происходящие в сложных процессах взаимодействия цифровой и традиционной социализации в смешанной реальности.

Цифровая социализация как непрерывный процесс адаптации изменяющегося человека к возможностям и рискам постоянно трансформирующейся социотехнологической среды требует смены парадигм и новых теоретических моделей исследования. В статье предложен трансдисциплинарный подход к анализу цифровой социализации и цифровой личности. Подобный теоретико-методологический подход является кумулятивным и открыт для разнообразных концепций и методов. Разработанная Л.С. Выготским и его последователями культурно-историческая теория развития психики, впитавшая в себя классические и современные гуманитарные и естественно-научные концепции, представляется наиболее перспективным базисом для исследования психологических особенностей цифровой реальности, способным выдержать вызовы «новой нормальности».

\section{Литература}

Асмолов, А. Г. (ред.). (2018). Mobilis in mobili: личность в эпоху перемен. М.: Издательский дом ЯСК. Асмолов, Г. А., Асмолов, А. Г. (2019). Интернет как генеративное пространство: историко-эволюционная перспектива. Вопросы психологии, 4, 3-28.

Бажанов, В. (2015). О феномене трансдисциплинарной научной революции. В кн. В. Бажанов, Р. В. Шольц (ред.), Трансдисциплинарность в философии и науке. Подходы. Проблемьь. Перспективы (с. 136-144). М.: Навигатор.

Василюк, Ф. Е. (1984). Психология переживания. Анализ преодоления критических ситуащий. М.: Изд-во Московского университета.

Вересов, Н. Н. (2016). Переживание как психологический феномен и теоретическое понятие: уточняющие вопросы и методологические медитации. Культурно-историческая психология, 12(3), 129-148. https://doi.org/10.17759/chp.2016120308 
Войскунский, А. Е. (2010). Психология и Интернет. М.: Акрополь.

Выготский, Л. С. (1982). Инструментальный метод в психологии. В кн. Л. С. Выготский, Полное собрание сочинений (в 6 т., т. 1, с. 103-108). М.: Педагогика.

Гусельцева, М. С. (2015). Психология и новые методологии: эпистемология сложного. Психологические исследования: электронный научный журнал, 8(42) 11. http://psystudy.ru/index.php/num/2015v8n42/1158-guseltseva42.html\#e3

Даль, В. (1980). Толковый словарь живого великорусского языка (в 4 т., т. 4). М.: Русский язык.

Иванов, Д. В. (2019). Экстернализм и теория расширенного сознания. Философия науки и техники, 25(2), 33-42. https://doi.org/10.21146/2413-9084-2019-24-2-33-42

Кастельс, М. (2016). Власть коммуникации. М.: Изд-во ВШЭ.

Клочко, В. Е. (2012). Когнитивная наука: от междисциплинарного дискурса к трансдисциплинарному ракурсу. Сибирский психологический журнал, 46, $23-32$.

Коул, М. (1997). Культурно-историческая психология - наука будущего. М.: Когито-центр; ИП РАН.

Маклюэн, М. (2005). Галактика Гутенберга. Становление человека печатающего. М.: Академический проект.

Маклюэн, М. (2007). Понимание медиа: внешние расширения человека. М.: Кучково поле.

Марцинковская, Т. Д. (2009). Переживание как механизм социализации и формирования идентичности в современном меняющемся мире. Психологические исследования: электронный научный журнал, 3(5). http://psystudy.ru/index.php/num/2009n3-5/177-marsinkovskaya5.html\#e3

Рубцова, О. В. (2019). Цифровые технологии как новое средство опосредования (Часть первая). Культурно-историческая психология, 15(3), 117-124. https://doi.org/10.17759/chp.2019150312

Солдатова, Г. У. (2018). Цифровая социализация в культурно-исторической парадигме: изменяющийся ребенок в изменяющемся мире. Социальная психология и общество, 9(3), 71-80. https://doi.org/10.17759/sps.2018090308

Солдатова, Г. У., Рассказова, Е. И. (2020). Итоги цифровой трансформации: от онлайн-реальности к смешанной реальности. Культурно-историческая психология, 1(4), 87-97. https://doi.org/10.17759/chp.2020160409

Солдатова, Г. У., Рассказова, Е. И., Нестик, Т. А. (2017). Цифровое поколение России: компетентность и безопасность. М.: Смысл.

Солдатова, Г. У., Чигарькова, С. В., Дренева, А. А., Кошевая, А. Г. (2020). Эффект Юлия Цезаря: типы медиамногозадачности у детей и подростков. Вопросы психологии, 66(4), 54-69.

Тоффлер, Э. (2002). Шок будущего. М.: АСТ.

Файола, Э., Войскунский, А. Е., Богачева, Н. В. (2016). Человек дополненный: становление киберсознания. Вопросы философии, 3, 147-162.

Фейгенберг, И. М. (2011). Человек Достроенный и этика. Цивилизация как этап развития жизни Земли. М.: ООО «Медицинское информационное агентство».

Шваб, К. (2016). Четвертая промышленная революция. Пошаговое руководство по изменениям, которые ждут человечество в ближайшие 100 лет. М.: Эксмо.

Ссылки на зарубежные источники см. в разделе References после англоязычного блока. 
Солдатова Галина Уртанбековна - профессор, кафедра психологии личности, факультет психологии, Московский государственный университет имени М.В. Ломоносова; Школа антропологии будущего, РАНХиГС, доктор психологических наук, профессор, академик PAO.

Сфера научных интересов: психология личности, социальная психология, этнопсихология, психология межкультурных коммуникаций, психология переговоров, киберпсихология.

Контакты: soldatova.galina@gmail.com

Войскунский Александр Евгеньевич - ведущий научный сотрудник, кафедра общей психологии, факультет психологии, Московский государственный университет имени М.В. Ломоносова, кандидат психологических наук.

Сфера научных интересов: психология Интернета, когнитивная психология, взаимодействие человека с компьютером.

Контакты: vae-msu@mail.ru

\title{
Socio-Cognitive Concept of Digital Socialization: A New Ecosystem and Social Evolution of the Mind
}

\author{
G.U. Soldatova ${ }^{\mathrm{a}, \mathrm{b}}$, A.E. Voiskounsky ${ }^{\mathrm{a}}$ \\ ${ }^{a}$ Lomonosov Moscow State University, 1 Leninskie Gory, Moscow, 119991, Russian Federation \\ ${ }^{b}$ Russian Presidential Academy of National Economy and Public Administration (RANEPA), 84 Prospect \\ Vernadskogo, Moscow, 119571, Russian Federation
}

\begin{abstract}
Within the framework of a transdisciplinary approach and based on years of empirical research, a socio-cognitive concept of digital socialization has been developed, reflecting the process of adaptation of a changing person to the opportunities and risks of a dynamic socio-technological environment. The key element of the concept of digital socialization is a hyperconnected, technologically upgraded digital personality as a part of a real personality; the concept reflects the current stage of the social and cognitive evolution of the human mind, when the developing consciousness actually merges with external tools (gadgets) and semiotic reality (the Internet). Digital technologies are being integrated into our cognitive and social system, determining the digital expansion (upgrade) of a person. Key dimensions of digital socialization are Internet hyperconnectivity, mixed reality, augmented personality, and digital sociality. Being hyperconnected to the Internet in mixed reality means not only the basic and defining characteristics of digital socialization for both adults and children, but also the main basis for the changes that are taking place with a person today. The extended self - a constantly developing cultural tool - is formed in its socio-technological embodiment, and it modifies the human ecosystem. The emerging and transforming personality expands and absorbs a technosystem as a significant element that promotes the implementation of psychological mechanisms of externalization and includes digital devices and computer programs along with methods of their application. A new anthropological type of digital man - Man Connected and Upgraded - lives in multiple realities and already interacts with inanimate systems (chat bots, household robots, etc.), so a paradigm change, an update of theoretical and methodological models is required. All this
\end{abstract}


determines the cumulative nature of the theoretical and methodological approach, based mainly on the Lev Vygotsky's (and his followers') cultural psychology, which has absorbed classical and modern humanitarian and natural-scientific concepts. This approach is a promising basis for studying the specifics of digital reality, capable of withstanding the challenges of the "new normality".

Keywords: socialization, digital socialization, transdisciplinarity, culture psychology, externalization, technosystem, hyperconnectivity, extended personality, upgraded self, mixed reality, new normality, digital sociality.

\section{References}

Asmolov, A. G. (Ed.). (2018). Mobilis in mobili: lichnost'v epokhu peremen [Mobilis in mobili: A personality in the time of change]. Moscow: Izdatel'skii dom YaSK.

Asmolov, G. A., \& Asmolov, A. G. (2019). The internet as a generative space: Historical-evolutional perspective. Voprosy Psikhologii, 4, 3-28. (in Russian)

Back, M. D., Stopfer, J. M., Vazire, S., Gaddis, S., Schmukle, S. C., Egloff, B., \& Gosling, S. D. (2010). Facebook profiles reflect actual personality, not self-idealization. Psychological Science, 21(3) 372374. https://doi.org/10.1177/0956797609360756

Bazhanov, V. (2015). O fenomene transdistsiplinarnoi nauchnoi revolyutsii [Transdisciplinarity Type of Scientific Revolution]. In V. Bazhanov \& R. V. Shol'ts (Eds.), Transdistsiplinarnost'v filosofii i nauke. Podhody. Problemy. Perspektioy [Transdisciplinarity in philosophy and science: Approaches, problems, prospects] (pp. 136-144). Moscow: Navigator.

Belk, R. (2016). Extended self and the digital world. Current Opinion in Psychology, 10, 50-54. https://doi.org/10.1016/j.copsyc.2015.11.003

Bronfenbrenner, U. (1979). The ecology of human development: Experiments by nature and design. Cambridge, MA: Harvard University Press.

Bronfenbrenner, U. (Ed.). (2004). Making human beings human: Bioecological perspectives on human development. Housand Oaks, CA: Sage Publ.

Brubaker, R. (2020). Digital hyperconnectivity and the self. Theory and Society, 49(5-6), 771-801. https://doi.org/10.1007/s11186-020-09405-1

Buheji, M., \& Sisk, C.V. (2020). You and the new normal:Jobs, pandemics, relationship, climate change, success, poverty, leadership and belief in the emerging new world. AuthorHouse.

Castells, M. (2016). Vlast' kommunikatsii [Communication power]. Moscow: HSE Publishing House. (Original work published 2009)

Clark, A., \& Chalmers, D. (1998). The extended mind. Analysis, 58(1), 7-19.

Cole, M. (1997). Kul'turno-istoricheskaya psikhologiya - nauka budushchego [Cultural psychology: A once and future discipline]. Moscow: Kogito-tsentr; IP RAN. (Original work published 1996)

Dal', V. (1980). Tolkovyi slovar' zhivogo velikorusskogo yazyka [Explanatory dictionary of the living great Russian language] (in 4 Vols., Vol. 4). Moscow: Russkij yazyk.

Faiola, A., Voiskounsky, A. E., \& Bogacheva, N. V. (2016). Augmented human beings: developing cyberconsciousness. Voprosy Filosofii, 3, 147-162. (in Russian) 
Feigenberg, I. M. (2011). Chelovek Dostroennyi i etika. Tsivilizatsiya kak etap razvitiya zhizni Zemli [The Upgraded Man and Ethics. Civilization as a stage in the development of life on Earth]. Moscow: Meditsinskoe informatsionnoe agentstvo.

Floridi, L. (2014). The Fourth revolution. How the infosphere is reshaping human reality. Oxford University Press.

Floridi, L. (2015). The onlife manifesto: Being human in a hyperconnected era. Cham, Switherland et al.: Springer.

Griffin, P., Belyaeva, A., \& Soldatova, G. (1992). Socio-historic concepts applied to observations of computer use. European Journal of Psychology of Education, 7(4), 269-286.

Gusel'tseva, M. S. (2015). Psychology and new methodologies: the epistemology of complexity. Psikhologicheskie Issledovaniya, 8(42), 11. http://psystudy.ru/index.php/eng/2015v8n42e/1179guseltseva42e.html (in Russian)

Ivanov, D. V. (2019). Eksternalizm i teoriya rasshirennogo soznaniya [Externalism and the theory of expanded consciousness]. Filosofiya Nauki i Tekhniki, 25(2), 33-42.

Johnson, G., \& Puplampu, K. (2008). A conceptual framework for understanding the effect of the Internet on child development: The ecological techno-subsystem. Canadian Journal of Learning and Technology, 34(1), 19-28.

Klochko, V. E. (2012). Cognitive science: from interdisciplinary discourse to transdisciplinary foreshortening. Sibirskii Psikhologicheskii Zhurnal [Siberian Journal of Psychology], 46, 23-32. (in Russian)

Martsinkovskaya, T. D. (2009). Emotional experience (perezhivanie) as socialization and identity formation mechanism in modern changing world. Psikhologicheskie Issledovaniya, 3(5). http://psystudy.ru/index.php/eng/2009n3-5e/189-marsinkovskaya5e.html (in Russian)

McLuhan, M. (2005). Galaktika Gutenberga. Stanovlenie cheloveka pechatayushchego [The Gutenberg galaxy: The making of typographic man]. Moscow: Akademicheskii proekt. (Original work published 1962)

McLuhan, M. (2007). Ponimanie media: vneshnie rasshireniya cheloveka [Understanding media: The extensions of man]. Moscow: Kuchkovo pole. (Original work published 1964)

Mossberger K., Tolbert, C. J., \& McNeal, R. S. (2007). Digital citizenship: The Internet, society, and participation. Cambridge, MA: MIT Press.

Otrel-Cass, K. (Ed.). (2019). Hyperconnectivity and digital reality: Towards the eutopia of being human. Cham, Switherland: Springer. https://doi.org/10.1007/978-3-030-24143-8

Paulus, M. P., Squeglia, L. M., Bagot K., Jacobus, J., Kuplicki, R., Breslin, F. J., Bodurka, J., Morris, A. S., Thompson, W. K., Bartsch, H., \& Tapert, S. F. (2019). Screen media activity and brain structure in youth: Evidence for diverse structural correlation networks from the ABCD study. NeuroImage, 185, 140-153. https://doi.org/10.1016/j.neuroimage.2018.10.040

Przybylski, A. K., \& Weinstein, N. (2013). Can you connect with me now? How the presence of mobile communication technology influences face-to-face conversation quality. Journal of Social and Personal Relationships, 30(3), 237-246. https://doi.org/10.1177/0265407512453827

Rubtsova, O. V. (2019). Digital media as a new means of mediation (Part One). KulturnoIstoricheskaya Psikhologiya [Cultural-Historical Psychology], 15(3), 117-124. https://doi.org/10.17759/chp.2019150312 (in Russian)

Schwab, K. (2016). Chetvertaya promyshlennay a revolyutsiya. Poshagovoe rukovodstvo po izmeneniyam, kotorye zhdut chelovechestvo v blizhaishie 100 let [The Fourth Industrial Revolution. A guided tour 
to changes that await humanity in the upcoming century]. Moscow: Eksmo. (Original work published 2016)

Skarbez, R., Smith, M., \& Whitton, M. C. (2021). Revisiting Milgram and Kishino's reality-virtuality continuum. Frontiers in Virtual Reality, 2, Article 647997. https://doi.org/10.3389/ frvir.2021.647997

Soldatova, G. U. (2018). Digital socialization in the cultural-historical paradigm: a changing child in a changing world. Sotsial'naya Psikhologiya i Obshchestvo [Social Psychology and Society], 9(3), 71-80. https://doi.org/10.17759/sps.2018090308 (in Russian)

Soldatova, G. U., Chigar'kova, S. V., Dreneva, A. A., \& Koshevaya, A. G. (2020). Julius Caesar's effect: Types of media multitasking in children and adolescents. Voprosy Psikhologii, 66(4), 54-69. (in Russian)

Soldatova, G. U., \& Rasskazova, E. I. (2020). Digital transition outcomes: from online reality to mixed reality. Kul'turno-Istoricheskaya Psikhologiya [Cultural-Historical Psychology], 16(4), 87-97. https://doi.org/10.17759/chp.2020160409 (in Russian)

Soldatova, G. U., Rasskazova, E. I., \& Nestik, T. A. (2017). Tsifrovoe pokolenie Rossii: kompetentnost' $i$ bezopasnost' [Digital generation of Russia: Competence and safety]. Moscow: Smysl.

Sparrow, B., Liu, J., \& Wegner, D. M. (2011). Google effects on memory: Cognitive consequences of having information at our fingertips. Science, 333(6043), 776-778. https://doi.org/10.1126/science. 1207745

Toffler, A. (2002). Shok budushchego [Future shock]. Moscow: AST. (Original work published 1970)

Vasilyuk, F. E. (1984). Psikhologiya perezhivaniya. Analiz preodoleniya kriticheskikh situatsii [The psychology of experiencing. Analysis of overcoming critical situations]. Moscow: Moscow University Press.

Veresov, N. N. (2016). Perezhivanie as a phenomenon and a concept: Questions on clarification and methodological meditations. Kul'turno-Istoricheskaya Psikhologiya [Cultural-Historical Psychology], 12(3), 129-148. https://doi.org/10.17759/chp.2016120308 (in Russian)

Voyskunskij, A. E. (2010). Psikhologiya i Internet [Psychology and the Internet]. Moscow: Akropol'.

Vygotskij, L. S. (1982). Instrumental'nyi metod v psikhologii [The instrumental method in psychology]. In L. S. Vygotsky, Polnoe sobranie sochinenii [Complete works] (in 6 Vols., Vol. 1, pp. 103108). Moscow: Pedagogika.

Yee, N. (2014). The Proteus paradox: How online games and virtual worlds change us - and how they don't. New Haven, CT; London, UK: Yale University Press.

Galina U. Soldatova - professor, Department of Psychology, Lomonosov Moscow State University; The Russian Presidential Academy of National Economy and Public Administration, DSc in Psychology, Professor, Full Member of the Russian Academy of Education.

Research Area: psychology of personality, social psychology, ethnic psychology, psychology of intercultural communications, psychology of negotiation, cyberpsychology.

E-mail: soldatova.galina@gmail.com

Alexander E. Voiskounsky - Lead Research Fellow, Department of Psychology, Lomonosov Moscow State University, PhD in Psychology.

Research Area: cyberpsychology, cognitive psychology, human-computer interaction.

E-mail: vae-msu@mail.ru 